\title{
Bisphenol A Effects in Aqueous Environment on Lemna minor
}

\author{
Cristian-Emilian Pop ${ }^{1,2, *} \mathbb{0}$, Sorin Draga ${ }^{3}$, Roxana Măciucă ${ }^{2,4}$, Roxana Niță ${ }^{3}$, Nicolae Crăciun ${ }^{5}$ \\ and Robert Wolff ${ }^{6}$ (I)
}

1 Department of Biochemistry and Molecular Biology, Faculty of Biology, University of Bucharest, 91-95 Splaiul Independenței Str., 050095 Bucharest, Romania

2 Non-Governmental Research Organization Biologic, 14 Schitului Str., 032044 Bucharest, Romania; contact@ngobiologic.com

3 R\&D Department, Biotehnos SA, 3-5 Gorunului Str., 075100 Otopeni, Romania; sorin.draga@biotehnos.com (S.D.); rnita@biotehnos.com (R.N.)

4 Department of Biology, Faculty of Biology, University of Bucharest, 91-95 Splaiul Independenței Str., 050095 Bucharest, Romania

5 Zoology Section, Department of Biochemistry and Molecular Biology, Faculty of Biology, University of Bucharest, 91-95 Splaiul Independentei Str., 050095 Bucharest, Romania; nicolai.craciun@bio.unibuc.ro

6 College of Nursing and Public Health, South University, 9 Science Ct., Columbia, SC 29203, USA; rwolff@southuniversity.edu

* Correspondence: pop.cristian-emilian@s.bio.unibuc.ro; Tel.: +40-740627944

check for updates

Citation: Pop, C.-E.; Draga, S.; Măciucă, R.; Niță, R.; Crăciun, N.; Wolff, R. Bisphenol A Effects in Aqueous Environment on Lemna minor. Processes 2021, 9, 1512. https://doi.org/10.3390/pr9091512

Academic Editor: Avelino

Núñez-Delgado

Received: 26 July 2021

Accepted: 23 August 2021

Published: 26 August 2021

Publisher's Note: MDPI stays neutral with regard to jurisdictional claims in published maps and institutional affiliations.

Copyright: (C) 2021 by the authors. Licensee MDPI, Basel, Switzerland. This article is an open access article distributed under the terms and conditions of the Creative Commons Attribution (CC BY) license (https:/ / creativecommons.org/licenses/by/ $4.0 /)$.
Abstract: The link between different plastic waste pollutants and their impact on the natural aquatic environment and food chain remains a constant and growing issue. Bisphenol A (BPA), a known endocrine disruptor produced in large quantities primarily in the industry of polycarbonate plastics, can accumulate in vegetal and animal tissue, thus magnifying through trophic levels. In this study we exposed viable specimens of the aquatic plant Lemna minor under controlled conditions to 50, 100 and 200 ppm BPA levels in order to partially observe the toxic effects of BPA. Colonies ceased to form during the exposure and chlorosis was present especially in the $100 \mathrm{ppm}$ group. Interestingly enough, a high density formation of non-fermenting bacteria as well as coliforms was also observed in the BPA exposed cultures but not in the control groups. The levels of Malondialdehyde (MDA) in the vegetal tissue indicated cellular insults and severe damage, results that were correlated with the HPLC BPA determined concentrations of $0.1 \%, 0.2 \%$ and $0.4 \%$.

Keywords: Bisphenol A; BPA; aqueous; ecotoxicity; bacteria; Lemna minor

\section{Introduction}

Plastic pollution induces an alarming impact on aquatic ecosystems, becoming a severe issue worldwide. The unprecedented accumulation of growing plastic waste pollutants in aquatic ecosystems leads to disturbances to ecosystems' structure and functions [1]. It has been determined that there are chemical additives in the composition of some microplastics that are known as reproductive toxins, carcinogens and mutagens [2]. These micropollutants can bioaccumulate in the food chain and the resulting trophic transfer of microplastics and chemical constituents can have a serious impact on the stability of the ecosystem [1].

Bisphenol A (BPA), a compound used in the production of polycarbonate plastics and epoxy resins, has been detected in aquatic ecosystems, with about 100 tons of BPA being released into the atmosphere annually during production [3]; this does not include plastic trash or BPA from thermal papers. Evidence of BPA has been discovered in river and marine sediments in variable concentrations $[4,5]$.

Both vegetal and animal tissues are able to absorb BPA, which has proven to be an important endocrine disruptor [6,7]. In the case of mammalian systems, BPA can interact with nuclear receptors, mimicking the action of natural hormones including progestins, estrogens, androgens, glucocorticoids, vitamin D3, thyroid and retinoid hormones. Through 
these interactions, BPA can affect the normal function of these receptors even in very low doses [8]. In vegetal organisms, BPA can accumulate in the tissue, interacting with lipids and therefore inducing modifications into the cell membrane which can lead to cell damage and, eventually, to apoptosis [9].

Aquatic floating plants such as Lemna minor have the capacity to accumulate for the removal of micropollutants. Lemna minor has a wide distribution around the world, a simple structure and can be easily cultivated. It can double its biomass in two days, growing faster than most other plants and proving to be an ideal test organism [10,11].

Few studies have explored the effects of BPA on macrophytic plants in aquatic environments. Adamakis et al. [12] found leaf elongation was impaired and defects in the cytoskeleton of a seagrass occurred at BPA concentrations that were environmentally relevant. In an industry sponsored study, Mihaich et al. [13] found a significant decrease in frond density and growth rate in Lemna gibba, but were dismissive of environmental impact. Lemna was shown to remove BPA from the water [14] due to uptake.

The objective of this paper was to identify the toxicity of BPA in the aquatic plant Lemna minor, known to be a sensitive test organism to pollutants. Viable specimens of Lemna minor were studied under controlled conditions to different BPA levels. The toxic effects of BPA were measured by lipid peroxidation, growth inhibition and the total chlorophyll content.

\section{Materials and Methods}

\subsection{Bisphenol A Aqueous Solution}

The protocol used to obtain the experimental Bisphenol A (BPA) aqueous solutions were performed after Motoyama et al. [15], in which 20, 10 and $5 \mathrm{mg}$ of BPA $\geq 99 \%$ (Sigma-Aldrich, Darmstadt, Germany) were dissolved in $1 \mathrm{~mL}$ anhydrous ethanol, then $99 \mathrm{~mL}$ of culture water was added. The azeotrope BPA containing solutions were stirred at $600 \mathrm{rpm}$ on a magnetic stirrer hotplate at $25^{\circ} \mathrm{C}$ for $2 \mathrm{~h}$; due to evaporation each solution was supplemented with $8 \mathrm{~mL}$ of distilled water to reach the total volume of $100 \mathrm{~mL}$. As the maximum solubility of BPA in water is $200-300$ ppm [16], a higher concentration was not used as it had no fundament.

\subsection{Lemna Minor Culturing Conditions}

For culturing Lemna minor, $500 \mathrm{~mL}$ of lake water was collected and vacuum filtered using qualitative filter papers grade 202 with 5-8 $\mu$ m retention (Frisenette, Knebel, Denmark). The filtered water was then re-filtered with sterile $0.22 \mu \mathrm{m}$ Polyethersulfone (PES) syringe filters (Isolab, Schweitenkirchen, Germany) in order to remove fine particles including bacteria and fungi prior to BPA being added, as stated above. Filtered water without BPA was used as the control culture media.

Mature, actively growing specimens of Lemna minor were selected, rinsed thoroughly with distilled water and then enclosed in sterile $400 \mathrm{~mL}$ capacity transparent tissue culture flasks (VWR, Philadelphia, PA, USA), each with $100 \mathrm{~mL}$ of the culture water containing $\mathrm{BPA}$ or the control. The specimens were incubated at $25^{\circ} \mathrm{C}$ under controlled circadian conditions: $12 \mathrm{~h}$ light/ $12 \mathrm{~h}$ dark, where the light was provided by a fluorescent $4000 \mathrm{~K}$ white light lamp with 300 lumens intensity. The experiment took place for 1 week at concentrations of 200, 100 and 50 ppm of BPA.

\subsection{Macroscopic Observations}

Lemna minor plants were evaluated macroscopically in order to observe budding formation and possible abnormalities. The culture water turbidity was measured at $\mathrm{A}_{600}$ against a blank, and Eosin Methylene Blue base (EMB base) (Himedia, Mumbai, India) plates were inoculated with culture water from the BPA experimental groups and control group. Apart from the control group, a separate group which contained only the culture water that was kept in the same experimental conditions was also assayed microbiologically. EMB base is a modification of Levine EMB Agar; without lactose, the peptone serves as a source of carbon, nitrogen, and other essential growth nutrients while eosin and methylene 
blue dyes differentiate between lactose fermenters and non-fermenters. The chromogenic media is used for the differentiation of Escherichia coli and Enterobacter aerogenes as well as for the rapid identification of Candida albicans, and is also recommended for the detection, enumeration and differentiation of members of the coliform group [17].

\subsection{Total Chlorophyll Content Assay}

Chlorophyll content was determined by first washing the plants with distilled water prior to their roots being removed, and then briefly dabbing them dry on paper towels before weighing [18]. Approximately $300 \mathrm{mg}$ of tissue was kept in $5 \mathrm{~mL}$ of anhydrous ethanol in the dark at $4{ }^{\circ} \mathrm{C}$ for $24 \mathrm{~h}$. The samples were gently shaken and 1:10 $(v / v)$ dilutions in anhydrous ethanol were made using the supernatant. A clear ethanol solution served as the reference blank, and the absorbance of the plant extracts was calculated from the ratio of the response of the extract solution to the reference blank, according to the equations: concentration in units of $\mu \mathrm{g} / \mathrm{mL}$ of chlorophyll $a=13.70\left(A_{665}\right)-5.76\left(A_{649}\right)$; and concentration in units of $\mu \mathrm{g} / \mathrm{mL}$ of chlorophyll $b=25.8\left(A_{649}\right)-7.60\left(A_{665}\right)$ [19].

\subsection{Lipid Peroxidation-TBARS Assay}

A thiobarbituric acid reactive substances (TBARS) assay was adapted after Buege and Aust, 1978 [20]. TBARS are formed as byproducts of lipid peroxidation (i.e., as degradation products of fats) determined as malondialdehyde (MDA), a pink compound that can be spectrophotometrically read. To perform the assay, plants were weighed and $10 \%$ homogenate was made in cold $0.154 \mathrm{M} \mathrm{KCl}$. The homogenate was then centrifuged for $15 \mathrm{~min}$ at $10.000 \mathrm{rpm}$ (Eppendorf Minispin Plus, Leipzig, Germany). The supernatant was collected in clean tubes and to each $500 \mu \mathrm{L}$ of supernatant, $500 \mu \mathrm{L}$ of $10 \%$ trichloroacetic acid (Fisher, New Jersey, NJ, USA) was added. The samples were then centrifuged at $3500 \mathrm{rpm}$ and the supernatant was collected. To $500 \mu \mathrm{L}$ of supernatant, $500 \mu \mathrm{L}$ of $0.67 \%$ thiobarbituric acid (Merck, Darmstad, Germany) was added. The samples were then kept on boiling water for $15 \mathrm{~min}$, left to cool and then measured at $531 \mathrm{~nm}$ (Shimadzu, Tokyo, Japan) against blank. Concentrations were measured using the molar extinction coefficient of $0.641 \times 10^{-5}$ to obtain the MDA concentration in $\mathrm{nM}$ [20].

\subsection{HPLC Analysis}

Lemna minor samples were placed at $-80^{\circ} \mathrm{C}$ in an ultrafreezer (Thermofisher, Lenexa, KS, USA) for $48 \mathrm{~h}$ and then cryodesiccated for 5 days. The resulting dry mass was weighed and HPLC analyzed. The system used was an Agilent series 1260 Infinity (Agilent, Santa Clara, CA, USA), equipped with a binary pump and DAD detector. Data analysis was performed via OpenLAB CDS software, version C 01.02. The chromatographic separation was made on a Kinetex C18 column $(100 \times 2.1 \mathrm{~mm}, 2.6 \mu \mathrm{m}$, Phenomenex, Torrance, CA, USA) at $35{ }^{\circ} \mathrm{C}$, using a mobile phase containing water-acetonitrile at 70:30 $(v / v)$ with isocratic elution, at $0.3 \mathrm{~mL} / \mathrm{min}$ flow rate, followed by column washing with $70 \%$ acetonitrile (Carlo Erba, Milano, Italy) and then re-equilibrated to the initial condition. The detection was monitored at $210 \mathrm{~nm}$; the injection volume was $2 \mu \mathrm{L}$.

Cryodesiccated samples were analyzed in duplicates, as follows: for each group $\approx 5 \mathrm{mg}$ of cryodesiccated sample was weighed and $1 \mathrm{~mL}$ of acetonitrile was added prior to a $20 \mathrm{~min}$ ultrasonification at $25^{\circ} \mathrm{C}$. The resulting extract was filtered through a $0.2 \mu \mathrm{m}$ PTFE filter (Agilent, Captiva EconoFilter, Santa Clara, CA, USA) and then HPLC analyzed.

For sample quantification, a standard solution of $\geq 99 \%$ Bisphenol A (Sigma-Aldrich, city, Germany) $1 \mathrm{mg} / \mathrm{mL}$ was prepared in LC-MS grade acetonitrile (Carlo Erba, Milano, Italy), dilutions were made at 10, 100 and $500 \mu \mathrm{g} / \mathrm{mL}$ concentrations in order to obtain a calibration curve (Figure 1). 


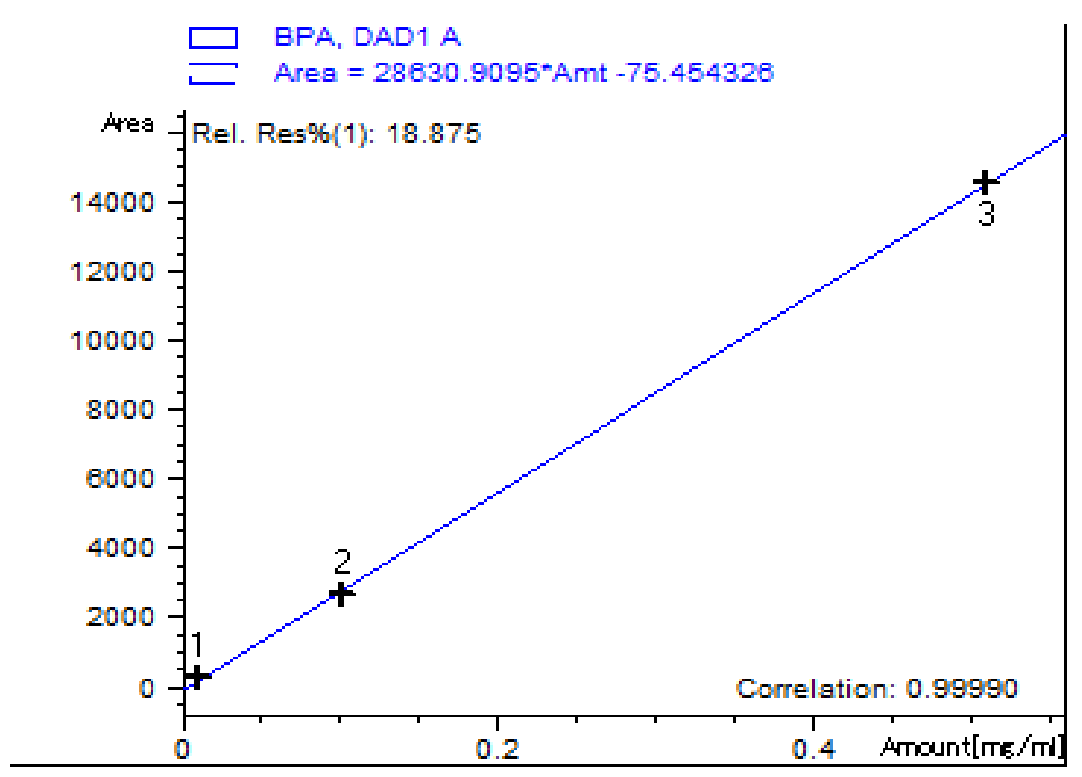

Figure 1. Bisphenol A calibration curve.

\section{Results}

\subsection{Macroscopic Observations}

Visual investigation revealed chlorosis (yellowing of leaf tissue) for the groups exposed to 200 and $100 \mathrm{ppm}$. No budding formation was observed. The $50 \mathrm{ppm}$ group presented normal leaf color, but with no budding formations, while the control group showed no alteration and presented with budding formations.

The Lemna minor control group as well as the culture water control group were clear with no significant $\mathrm{OD}_{600}$ (Optical Density) increase against blank, followed by an increase at $50 \mathrm{ppm}$ that peaked at $100 \mathrm{ppm}$ and decreased for the $200 \mathrm{ppm}$ group (Figure 2). Biofilms were observed on the roots of plants in the $100 \mathrm{ppm}$ group but not in the other groups. The EMB culture plates were read after a $24 \mathrm{~h}$ incubation at $35^{\circ} \mathrm{C}$ and revealed luxuriant colonies of non-fermenting Gram-negative bacteria, as well as punctiform colonies of Escherichia coli. The colonies were identified on the chromogenic media by a colorless aspect for non-fermenting Gram-negative bacteria and a pink color for Klebsiella aerogenes colonies, respectively blue-black with a green metallic sheen for Escherichia coli colonies. No colonies were present on the plates inoculated from the Lemna minor control group and neither from the culture media control group.

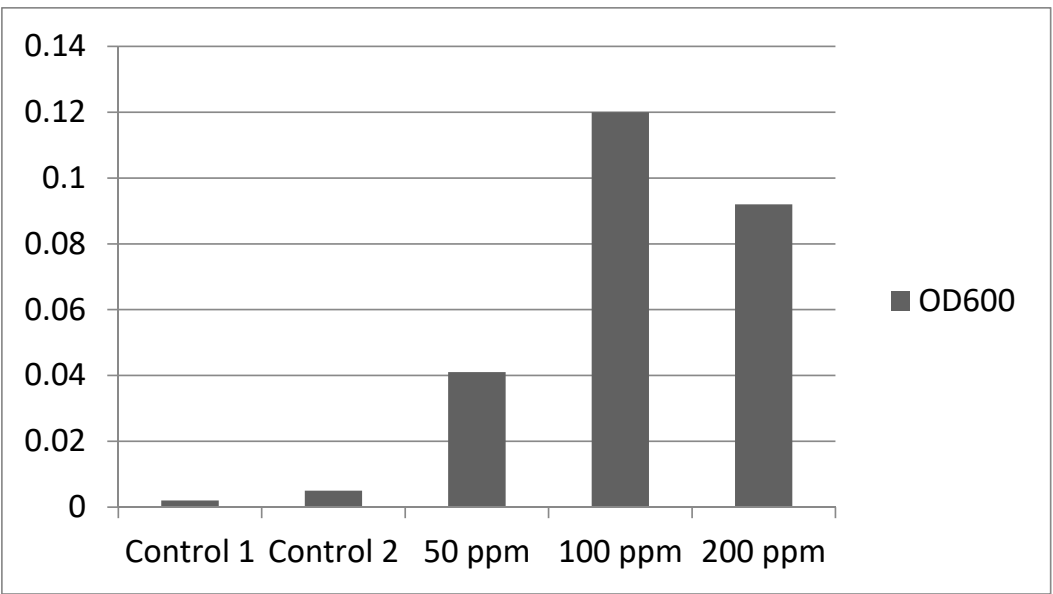

Figure 2. Spectrophotometric measurements of the culturing media turbidity at $600 \mathrm{~nm}\left(\mathrm{OD}_{600}\right)$. 


\subsection{Total Chlorophyll Content}

Chlorophyll levels were found at their lowest in the $100 \mathrm{ppm}$ group, followed by the 200 and $50 \mathrm{ppm}$ groups (Figures 3 and 4), the results are multiplied by a factor of 10 due to the 1:10 dilution made to perform the readings.

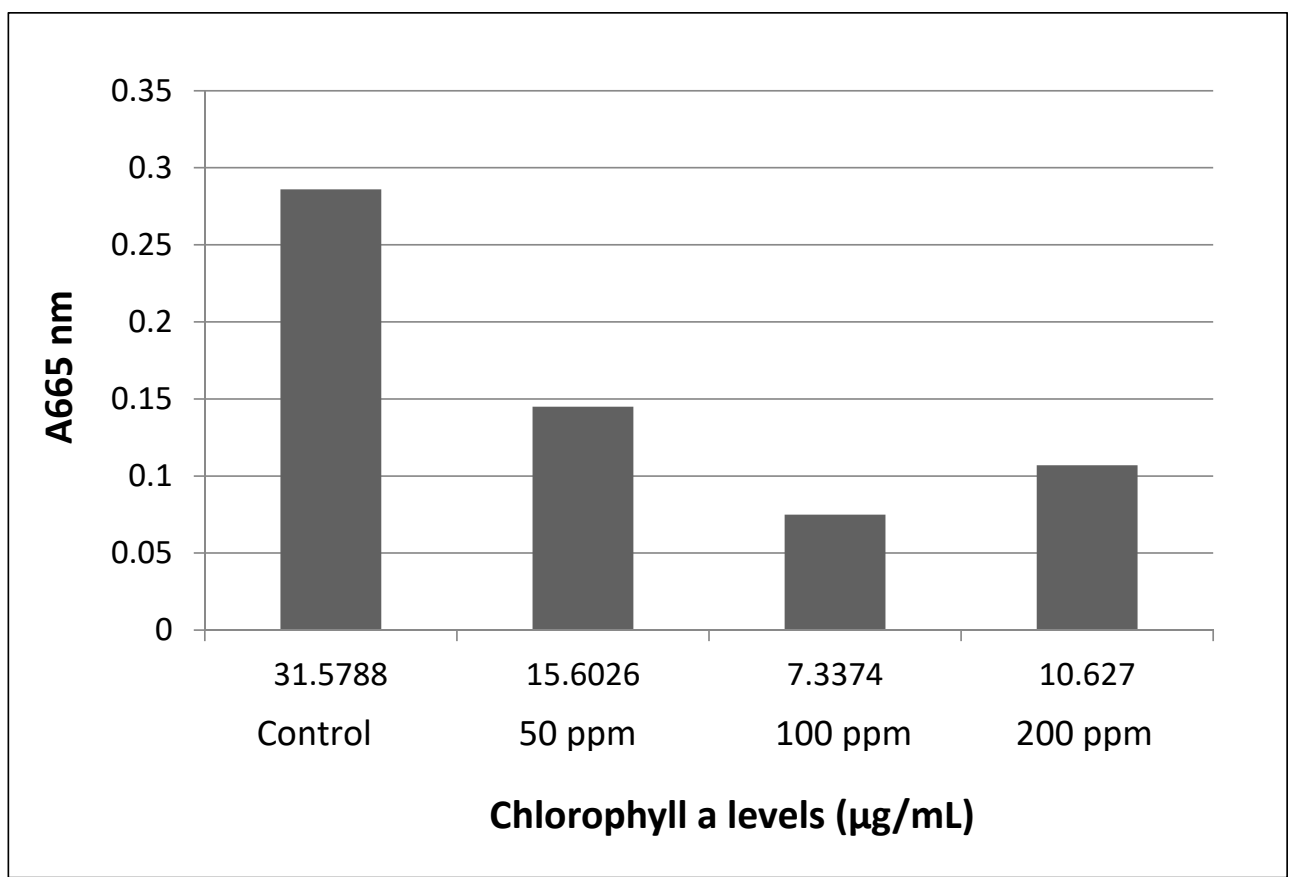

Figure 3. Chlorophyll $a$ content at $665 \mathrm{~nm}$ absorption.

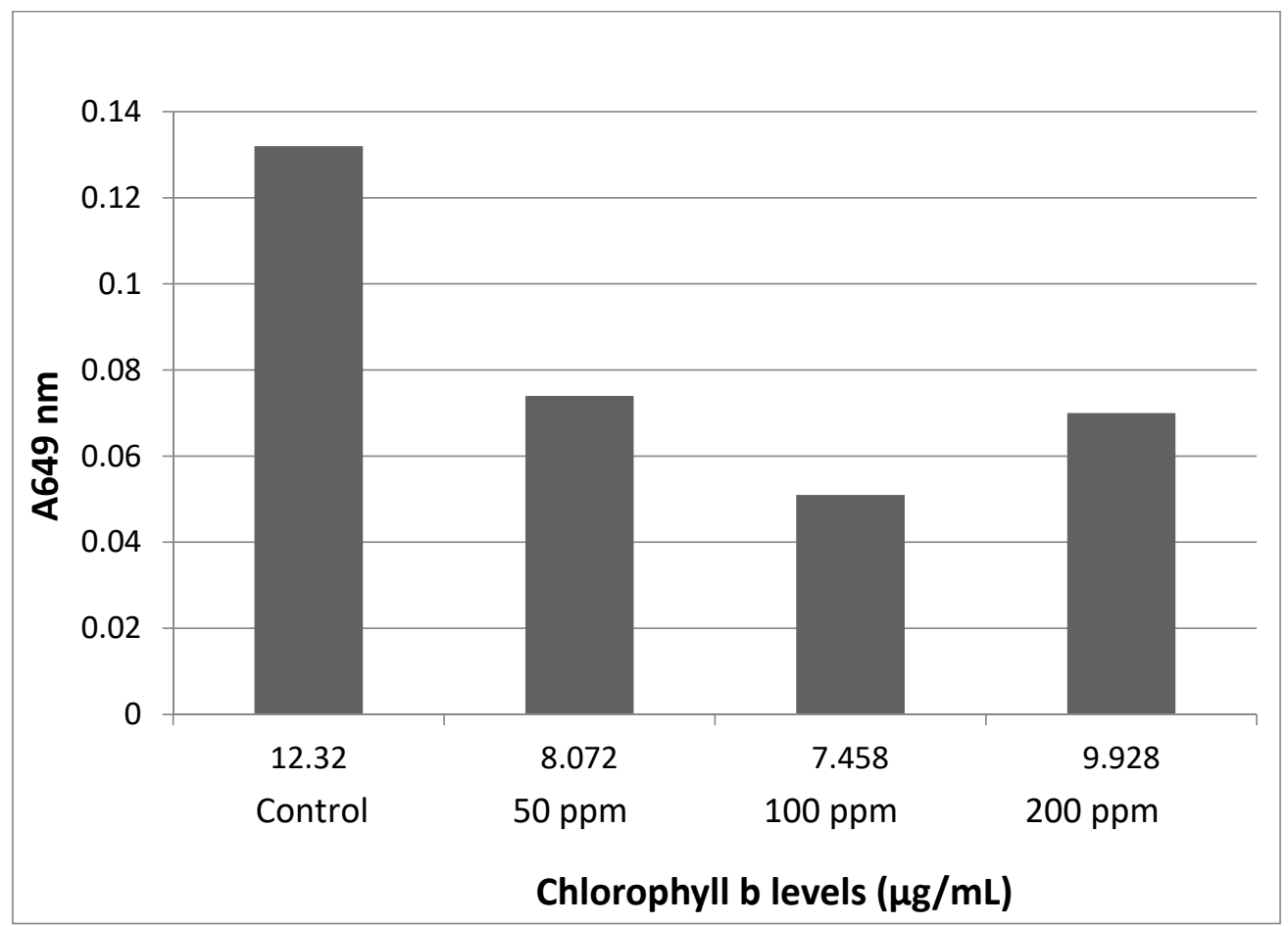

Figure 4. Chlorophyll $b$ content at $649 \mathrm{~nm}$ absorption.

\subsection{Oxidative Stress Levels}

TBARS Assay results showed high absorbance at $531 \mathrm{~nm}$ for the control and $50 \mathrm{ppm}$ groups but low absorbance with small variations for the 100 and 200 ppm groups, the 
measurements were made against blank, which represented all the reagents in the same ratio that underwent the same thermal treatment but without the plant tissue. MDA concentration was measured using the formula:

MDAconcentrationinnM $=\frac{\text { Absorbanceat531nm }}{\text { molarextinctioncoeficient }(\varepsilon)}$, where $\varepsilon=0.641 \times 10^{-5}$.

The results are shown in Figure 5, converted to $\mu \mathrm{M}$.

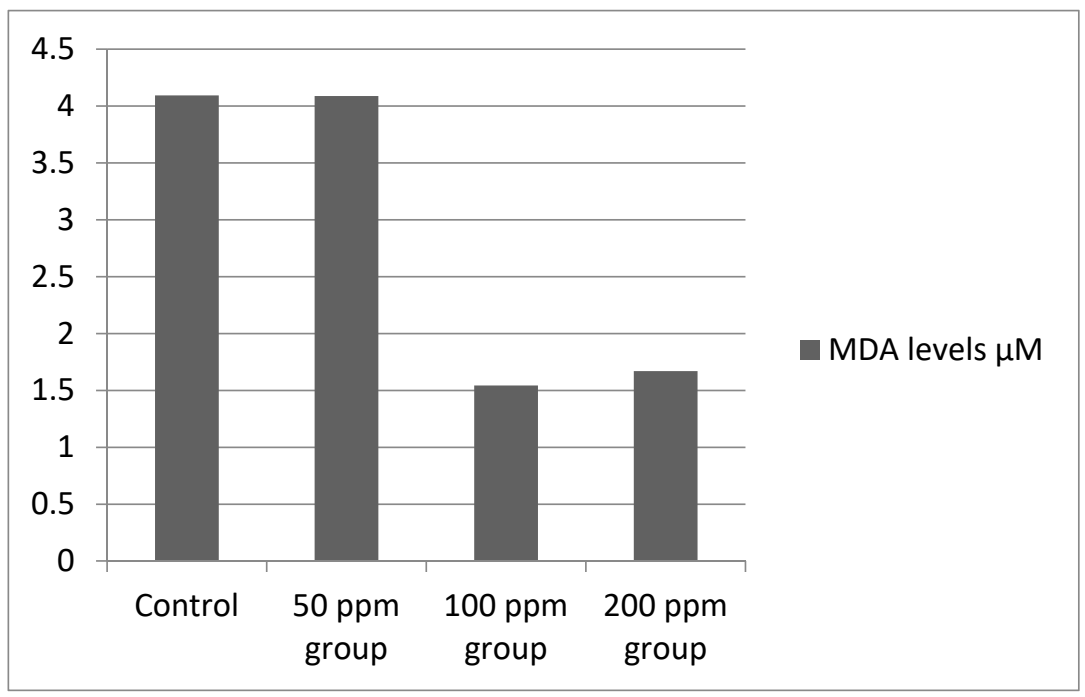

Figure 5. MDA content at $531 \mathrm{~nm}$ absorption.

\subsection{HPLC Results}

The HPLC chromatograms (Figure 6) revealed BPA absorption in all three exposed groups for P1, P2, P3 and none detected in the control group P4. The analysis was performed in duplicate where P1-1, P1-2 represent plants exposed to 50 ppm; P2-1, P2-2 represent plants exposed to 100 ppm; P3-1, P3-2 represent plants exposed to 200 ppm and P4-1, P4-2 represent the plant control group. The numerals I, II and III represent the culture water with BPA at 50,100 and 200 ppm. (Table 1).

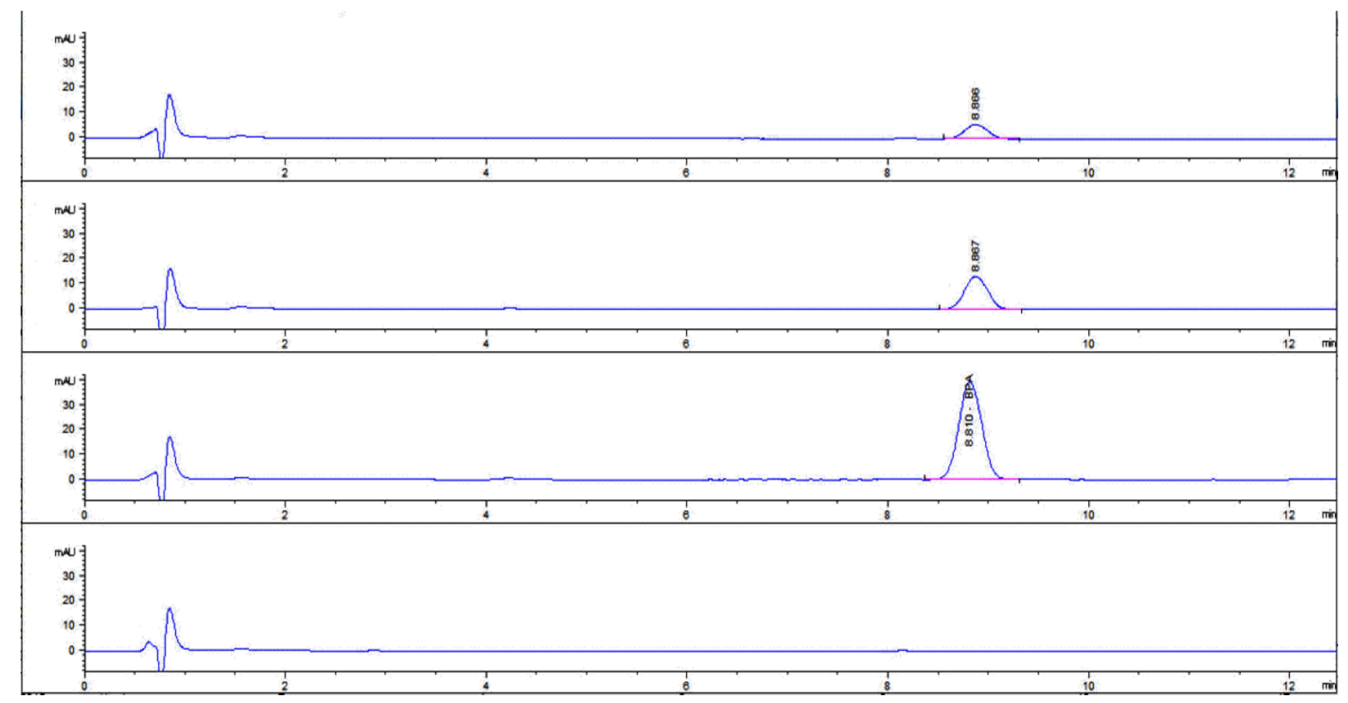

Figure 6. HPLC Chromatogram representing, from the bottom to the top, the samples P4-1, P3-1, P2-1 and P1-1. 
Table 1. BPA content in Lemna minor samples.

\begin{tabular}{cccc}
\hline Sample & Sample Mass $(\mathbf{m g})$ & $\begin{array}{c}\text { BPA in Sample } \\
\text { Extract }(\mathbf{m g} / \mathbf{m L})\end{array}$ & $\begin{array}{c}\text { BPA in Sample Extract } \\
\text { Expressed in Percentage (\%) }\end{array}$ \\
\hline P1-1 & 5.1 & 0.0057 & 0.11 \\
P1-2 & 5.3 & 0.0063 & 0.12 \\
\hline P2-1 & 5 & 0.009955 & 0.20 \\
P2-2 & 5 & 0.0128 & 0.26 \\
\hline P3-1 & 5.2 & 0.0243 & 0.47 \\
P3-2 & 5.4 & 0.0257 & 0.48 \\
P4-1 & 5.2 & 0 & 0 \\
P4-2 & 5.3 & 0 & \\
\hline I & & 0.045 & \\
II & & 0.102 & \\
III & & 0.201 & \\
\hline
\end{tabular}

\section{Discussion}

Effects such as chlorosis and cessation of bud formation were observed macroscopically, as well as high densities of non-lactose fermenting bacteria that were confirmed by inoculation on plates with the EMB selective media. The estrogenic effect of BPA as well as its capacity to stimulate abnormal growth was first accidentally discovered after autoclaving polycarbonate culture flasks in a study to determine whether Saccharomyces cerevisiae produced estrogens [21,22], the culture media was prepared using distilled water autoclaved in the polycarbonate flasks from which BPA leaked. Although the microbial growth was facilitated in our study by BPA levels, chlorosis and cessation of budding could be linked to the multiple effects of BPA.

According to some authors [21-23] alterations of chlorophyll content can serve as an indicator of the physiological status of a photosynthetic organism. Therefore, it has been frequently used in ecotoxicological studies for the assessment of toxicity of inorganic and organic chemicals. It is thus possible to conclude that BPA challenged the production of photosynthetic pigments impairing photosynthesis in this study. One study found that higher microbial densities with added bacteria appeared to be cause of the degradation of chlorophyll a in two marine algae [24]. It is possible that the lower chlorophyll levels found in this study corresponding to higher optical density readings may be at least partially responsible for the results obtained. This may account for the reduced chlorophyll levels seen in the $100 \mathrm{ppm}$ BPA cultures as well as the somewhat reduced levels in the $200 \mathrm{ppm}$ BPA cultures. While the apparent levels of bacteria seem to be associated with a reduction in chlorophyll, the causative factors are not clear. While the increase in optical density is expected in the experimental cultures, and the reduction in chlorophyll levels probably related in part to the BPA concentrations, the effect of the BPA on bacterial growth and chlorophyll degradation needs to be fully explored. Lipid peroxidation was a distinctive and sensitive parameter showing the degree to which reactive oxygen species induced damage, as the biphenolic compound had a surprising effect on L. minor which was ineffective in coping with the cellular level insults of BPA for 100 and 200 ppm concentrations. This resulted in an interestingly low lipid peroxidation concentration and therefore low absorbance values at $\mathrm{A}_{531}$ compared to the control and $50 \mathrm{ppm}$ groups.

A molecular dynamics simulation study [9] indicated that BPA can easily enter the membrane from the aqueous phase in an isolated phospholipid bilayer. With the increasing concentrations of BPA in the membrane, BPA tends to aggregate and form into cluster while dipalmitoyl phosphatidylcholine (DPPC) lipids are pulled out and adsorbed on the cluster surface, leading to membrane pore formation. Observations indicated that the lipid extraction results mainly from the dispersion interactions between BPA cluster and lipid tails, as well as weak electrostatic attractions between lipid headgroups and the two 
hydroxyl groups on BPA. Such lipid extraction and pore formation cause cell membrane damage that leads to chlorosis and apoptosis, revealing another cytotoxicity aspect of BPA.

\section{Conclusions}

Lemna minor, a macrophyte known for it's abilities in water purification processes, demonstrated a BPA absorption of $\approx 0.1 \%, 0.2 \%$ and $0.4 \%$ during the time in culture in this study. Consequences will include detrimental effects regarding its mitosis, cellular membrane integrity and viability. All of these could occur with significant environmental damage to all aquatic organisms.

The findings determined that the lack of budding formations at all experimental concentrations is an important concern from BPA pollution of aquatic systems. The low concentrations of Chlorophyl a in the group exposed to $100 \mathrm{ppm}$, and a part of the results in the 200 ppm cultures, could be explained by both the toxic effects directly, the high density of the microbial community, or both of these in concert.

Although toxic to eukaryotic organisms, the hormone-like properties of BPA appears to strongly enhance growth in some bacteria that are naturally found in freshwater environments. The detection of the increased bacterial growth of the coliform bacteria and production of a biofilm on the plants in the $100 \mathrm{ppm}$ culture is a new and potentially important finding. This may occur through the epigenetic actions of BPA [25]

The implications of BPA pollution causing an increase in the growth of some bacterial species raises many important ecological questions. The changes in bacterial composition of the culture microbiome and growth not shown in other culture conditions raises other critical questions regarding ecosystem functioning and the complex effects of this endocrine disruptor.

A review [26] found that surface waters exceeded the proposed predicted no-effect concentrations in Europe $53.1 \%$ of the time, and $34.6 \%$ in North America. These data along with the new findings in this report indicate a clear and urgent need to understand the effect of BPA on microorganisms and the direct or indirect effect on chlorophyll in surface waters.

Author Contributions: Conceptualization, C.-E.P., R.W. and N.C.; methodology, C.-E.P., S.D. and R.N.; software, S.D.; investigation, N.C.; resources, C.-E.P. and N.C.; data curation, R.W.; writingoriginal draft preparation, R.M., C.-E.P.; writing-review and editing, R.M., C.-E.P., R.W.; funding acquisition, C.-E.P. and N.C. All authors have read and agreed to the published version of the manuscript.

Funding: This research was made possible with the support of the Non-Governmental Research Organization Biologic.

Institutional Review Board Statement: Not applicable.

Informed Consent Statement: Not applicable.

Conflicts of Interest: The authors declare no conflict of interest.

\section{References}

1. Laws, A.E. Aquatic Pollution: An Introductory Text, 4th ed.; Wiley: Hoboken, NJ, USA, 2017; pp. 12-13. ISBN 978-1-119-30450-0.

2. Wright, S.L.; Kelly, F.J. Plastic and Human Health: A Micro Issue? Environ. Sci. Technol. 2017, 51, 6634-6647. [CrossRef] [PubMed]

3. Markey, C.M.; Michaelson, C.L.; Sonnenschein, C.; Soto, A.M. Alkylphenols and Bisphenol A as environmental estrogens. In The Handbook of Environmental Chemistry. Part L, Endocrine Disruptors_Part I; Metzler, M., Ed.; Springer: Berlin/Heidelberg, Germany, 2001; Volume 3, pp. 129-153.

4. Flint, S.; Markle, T.; Thompson, S.; Wallace, E. Bisphenol A exposure, effects, and policy: A wildlife perspective. J. Environ. Manag. 2012, 104, 19-34. [CrossRef]

5. Koh, C.H.; Khim, J.S.; Villeneuve, D.L.; Kannan, K.; Giesy, J.P. Characterization of trace organic contaminants in marine sediment from Yeongil Bay, Korea: 1. Instrumental analyses. Environ. Pollut. 2006, 142, 39-47. [CrossRef] [PubMed]

6. $\quad$ Oehlmann, J.; Schulte-Oehlmann, U.; Kloas, W.; Jagnytsch, O.; Lutz, I.; Kusk, K.O.; Wollenberger, L.; Santos, E.M.; Paull, G.C.; Van Look, K.J.; et al. A critical analysis of the biological impacts of plasticizers on wildlife. Philos. Trans. R. Soc. B Biol. Sci. 2009, 364, 2047-2062. [CrossRef] [PubMed] 
7. Canesi, L.; Fabbri, E. Environmental Effects of BPA: Focus on Aquatic Species. Dose Response 2015, 13, 1559325815598304. [CrossRef]

8. Li, L.; Wang, Q.; Zhang, Y.; Niu, Y.; Yao, X.; Liu, H. The Molecular Mechanism of Bisphenol A (BPA) as an Endocrine Disruptor by Interacting with Nuclear Receptors: Insights from Molecular Dynamics (MD) Simulations. PLoS ONE 2015, 10, e0120330. [CrossRef]

9. Chen, L.; Chen, J.; Zhou, G.; Wang, Y.; Xu, C.; Wang, X. Molecular Dynamics Simulations of the Permeation of Bisphenol A and Pore Formation in a Lipid Membrane. Sci. Rep. 2016, 6, 33399. [CrossRef] [PubMed]

10. Chen, G.; Fang, Y.; Huang, J.; Zhao, Y.; Li, Q.; Lai, F.; Xu, Y.; Xueping, T.; He, K.Z.; Jin, Y.; et al. Duckweed systems for eutrophic water purification through converting wastewater nutrients to high-starch biomass: Comparative evaluation of three different genera (Spirodela polyrhiza, Lemna minor and Landoltia punctata) in monoculture or polyculture. RSC Adv. 2018, 8, 17927-17937. [CrossRef]

11. Fekete-Kertész, I.; Kunglné-Nagy, Z.; Gruiz, K.; Magyar, Á.; Farkas, É.; Molnár, M. Assessing Toxicity of Organic Aquatic Micropollutants Based on the Total Chlorophyll Content of Lemna minor as a Sensitive Endpoint. Period. Polytech. Chem. Eng. 2015, 59, 262-271. [CrossRef]

12. Adamakis, I.S.; Malea, P.; Panteris, E. The effects of Bisphenol A on the seagrass Cymodocea nodosa: Leaf elongation impairment and cytoskeleton disturbance. Ecotoxicol. Environ. Saf. 2018, 157, 431-440. [CrossRef]

13. Mihaich, E.M.; Friederich, U.; Caspers, N.; Hall, A.T.; Klecka, G.M.; Dimond, S.S.; Staples, C.A.; Ortego, L.S.; Hentges, S.G. Acute and chronic toxicity testing of Bisphenol A with aquatic invertebrates and plants. Ecotoxicol. Environ. Saf. 2009, 72, 1392-1399. [CrossRef] [PubMed]

14. Garcia-Rodríguez, A.; Matamoros, V.; Fontàs, C.; Salvadó, V. The influence of Lemna sp. and Spirogyra sp. on the removal of pharmaceuticals and endocrine disruptors in treated wastewaters. Int. J. Environ. Sci. Technol. 2014, 12, 2327-2338. [CrossRef]

15. Motoyama, A.; Suzuki, A.; Shirota, O.; Namba, R. Direct determination of Bisphenol A and nonylphenol in river water by column-switching semi-microcolumn liquid chromatography/electrospray mass spectrometry. Rapid Commun. Mass Spectrom. 1999, 13, 2204-2208. [CrossRef]

16. EU; European Union Risk Assessment Report, CAS: 80-05-7 EINECS No: 201-245-8, Environment Addendum of April 2008, 4,4'-ISOPROPYLIDENEDIPHENOL (Bisphenol-A), Part1 Environment; Available from, as of Nov 13, 2012. Available online: https:/ / publications.jrc.ec.europa.eu/repository/bitstream/111111111/15063/1/lbna24588enn.pdf (accessed on 20 June 2021).

17. Greenberg, A.E.; Trussell, R.R.; Clesceri, L.S. (Eds.) Standard Met for the Examination of Water and Wastewater, 20th ed.; APHA: Washington, DC, USA, 1998.

18. Brain, R.A.; Solomon, K.R. A protocol for conducting 7-day daily renewal tests with Lemna gibba. Nat. Protoc. 2007, 2, 979-987. [CrossRef]

19. Porra, R.J.; Thompson, W.A.; Kriedemann, P.E. Determination of accurate extinction coefficients and simultaneous equations for assaying chlorophylls a and b extracted with four different solvents: Verification of the concentration of chlorophyll standards by atomic absorption spectroscopy. Biochim. Biophys. Acta 1989, 975, 384-394. [CrossRef]

20. Buege, J.A.; Aust, S.D. Microsomal lipid peroxidation. Methods Enzymol. 1978, 52, 302-310. [PubMed]

21. Krishnan, A.V.; Stathis, P.; Permuth, S.F.; Tokes, L.; Feldman, D. Bisphenol-A: An estrogenic substance is released from polycarbonate flasks during autoclaving. Endocrinology 1993, 132, 2279-2286. [CrossRef]

22. Eaton, A.D.; Clesceri, L.S.; Greenberg, A.E. Standard Methods for the Examination of Water and Wastewater, 19th ed.; American Public Health Association, American Water Works Association, and Water Environment Federation: Washington, DC, USA, 1995.

23. Dogan, M.; Saygideger, S.D.; Ugur Colak, U. Effect of lead toxicity on aquatic macrophyte Elodea canadensis Michx. Bull. Environ. Contam. Toxicol. 2009, 83, 249-254. [CrossRef]

24. Szymczak-Żyla, M.; Kowalewska, G.; Louda, J.W. The influence of microorganisms on chlorophyll a degradation in the marine environment. Limnol. Oceanogr. 2008, 53, 851-862. [CrossRef]

25. Cimmino, I.; Fiory, F.; Perruolo, G.; Miele, C.; Beguinot, F.; Formisano, P.; Oriente, F. Potential Mechanisms of Bisphenol A (BPA) Contributing to Human Disease. Int. J. Mol. Sci. 2020, 21, 5761. [CrossRef]

26. Corrales, J.; Kristofco, L.A.; Steele, W.B.; Yates, B.S.; Breed, C.S.; Williams, E.S.; Brooks, B.W. Global Assessment of Bisphenol A in the Environment: Review and Analysis of Its Occurrence and Bioaccumulation. Dose-Response 2015, 13, 1559325815598308. [CrossRef] [PubMed] 